\title{
A JOURNAL FOR PHARMACY PROFESSIONALS
}

Last July I was asked to head a task force with the mission of developing a journal for the Academy of Managed Care Pharmacy. We began with an initial teleconference to outline the scope and mission of the journal. A long, intricate' process ensued, with a goal of developing a peer-reviewed academic literary resource devoted to professional and scientific advancement of pharmacists and application of pharmaceutical care for all patients in today's health care system. Through the hard work of the task force and the dedication of the AMCP Board of Directors and staff, the Journal of Managed Care Pharmacy has become a reality.

\section{MOVING PHARMACY INTO THE FUTURE}

The new integratèd continuum of disease management has emerged with the purpose of achieving defined outcomes that improve a patient's quality of life. No longer are any pharmacistsincluding those in independent or chain community pharmacy-practicing in a segmented environment disconnected from a managed healthcare system. To survive, the future pharmacist must maintain professional activism and an expanded vision of pharmacy practice. Pharmacists must be able to practice fiscal responsibility while ba1ancing the needs of individual patients given aggregate population resources limited by capitation.

This futuristic model of healthcare affords pharmacists new opportunities and challenges. Pharmacists will be a part of the development of treatment protocols and interventions to prevent patient noncompliance. In a practice environment in which the pharmacist has access to complete data and can communicate with the patient, payment for cognitive services will become a reality. The outpatient pharmacy is a logical place for the screening of patients with routine medical problems and initiation of therapy in a managed health care environment.

\section{MISSION \& GOAL}

$J M C P$ is the first

peer-reviewed journal that documents the practices and principles of managed care pharmacy The journal's mission is to reach out to the pharmacy practitioner dedicated to advancing pharmacy's contribution to patient care in managed healthcare systems.

Like the recent bylaws change broadening the Active Member definition, the Journal is also an effort to reach out to the pharmacy practitioner who is committed to improved patient care, health outcomes, and fiscal responsibility This first peerreviewed journal dedicated to

\section{AMCP Journal Task Force Members}

\begin{tabular}{|c|c|}
\hline Shawn Burke (Organizational & Dennis L. Houghton \\
\hline Affairs Liaison) & Systems Consulting Company \\
\hline $\begin{array}{l}\text { Humana Health Care Plans } \\
\text { Kansas City, MO }\end{array}$ & Westlake Village, CA \\
\hline $\begin{array}{l}\text { John Hopkins (Board Liaison) } \\
\text { Rocky Mountain HMO } \\
\text { Grand Junction, CO }\end{array}$ & $\begin{array}{l}\text { Scott A. Larson } \\
\text { Schering Sales Corporation } \\
\text { Miami Lakes, FL }\end{array}$ \\
\hline $\begin{array}{l}\text { Louise J. Sargent (Chairperson) } \\
\text { PCS Health Systems }\end{array}$ & $\begin{array}{l}\text { Suzanne Rivkin } \\
\text { Farmington Hills, MI }\end{array}$ \\
\hline Minneapolis, MN & William N. Tindall \\
\hline Grace Fong (AMCP Publications & Ellen Osborne \\
\hline Committee Chair) & AMCP Staff \\
\hline Santa Rosa, CA & Alexandria, VA \\
\hline
\end{tabular}

articulating the managed care pharmacy perspective sets $J M C P$ apart from other publications. To that end $J M C P$ has crafted its mission statement:

$\nabla \mathrm{JMCP}$, as the official journal of the Academy of Managed Care Pharmacy, provides applied, professional, and scientific information to advance pharmacys contribution to patient care in managed healthcare systems.

\section{SCOPE \& CONTENT}

The contents of $J M C P$ will provide professional and scientific information that can be applied to your practice today The journal will help you by quenching your professional thirst for knowledge and enable you to dedicate your pharmacy practice to patient care by improving outcomes and fiscal responsibility.

The Journal will be organized around four types of peer-reviewed material and 10 departments. Additionally, feature articles on current issues and Spotlight articles on managed care companies will broaden each issue.

The peer-reviewed sections are Comparative Research (studies in which the scientific method is used to test hypotheses); Review Articles (summaries of recent clinical, economic, or management literature); and Descriptive Reports (practical solutions to real problems).

The departments in $J M C P$ will be these:

$\nabla$ Feedback (letters)

$\checkmark$ Perspectives (editorials)

$\nabla$ Trends (news)

$\boldsymbol{\nabla}$ Pipeline (new drugs)

$\nabla$ Caveats (legal and regulatory news)

$\boldsymbol{\nabla}$ Profiles (case management)

$\boldsymbol{\nabla}$ Media (current literature)

$\boldsymbol{\nabla}$ Events (calendar)

$\boldsymbol{\nabla}$ Impressions (about the cover) 


\section{PERSPECTIVES}

\section{$\boldsymbol{\nabla}$ Proficiency (continuing education material)}

A mission of the journal is to become an invaluable resource for pharmacy practitioners and students. JMCP promises to become "must reading" for our membership and the managed care community as a whole. You as a practicing pharmacy professional know what is important and what information is needed to advance pharma- cy's contribution to patient care in to day's rapidly changing healthcare system. I encourage you to submit your material for publication in the Journal of Managed Care Pharmacy. JMCP is a new membership benefit created to retain current AMCP members, attract new ones, and reach a vast readership of decision-makers in the pharmacy and managed care communities.

\section{AN OPEN FORUM FOR PHARMACY}

In the short time I have been involved with AMCP, I have been extremely impressed with the dedication of its members in creating a home for pharmacy professionals and in incorporating the principles and ideals of pharmaceutical care for patients as the standard of pharmacy practice. JMCP will aid in both these efforts.
I wish to thank those who enabled me to serve AMCP and the pharmacy profession as the Editor-in-Chief of JMCP. Use the new journal to your benefityour contributions and support will contribute to the development of an open forum for communication of ideas, concepts, and controversies within the community of pharmacy professionals.

Louise]. Sargent, R.Ph., M.S. Editor-in Chief, JMCP

\section{by Jay Messeroff, RPh}

Twenty-five years ago, I had the honor and privilege to help launch the Journal of Managed Care Pharmacy (JMCP) during my tenure as president of the Academy of Managed Care Pharmacy (AMCP). At that time, AMCP was home to managed care pharmacists who were responsible for the pharmaceutical needs of 60 million lives. Emerging roles for managed care pharmacists included formulary development, disease management, education, outcomes research, and policy analysis.

Fast forward to today, and many things have changed. In 1983, Boots Pharmaceuticals aired the first broadcast television commercial for its pain reliever drug Rufen (ibuprofen). It would take the U.S. Food and Drug Administration 14 more years to permit prescription drug companies to formally publicize their products directly to consumers (direct-to-consumer television advertisements were legalized in 1997). Direct-toconsumer marketing budgets jumped from $\$ 1.3$ billion in 1997 to more than $\$ 6$ billion in 2016, an increase of 361\%.

The Affordable Care Act was passed in 2010, superseding the Health Maintenance Organization (HMO) Act passed in 1973. While the HMO Act promoted the development of HMOs and required employers to offer HMO insurance options to employees, shifting away from the fee-for-service model, the Affordable Care Act went many steps further, reducing the percentage of uninsured people in America. One major change included health care coverage for adults with pre-existing conditions, which was previously unavailable.
The importance of managing pharmaceutical spend while providing quality outcomes is greater than ever, and AMCP has evolved over time to meet these needs. Today, AMCP members work to improve the lives of nearly 300 million Americans served by private and public health plans, pharmacy benefit management firms, and emerging health care delivery models.

AMCP is no longer just the home for managed care pharmacists. Membership has grown to over 8,000 health care professionals and now includes pharmacists, physicians, nurses, physician assistants, pharmacy technicians, and students.

To foster learning in managed care, AMCP has developed experiential training programs to address the many facets of managed care pharmacy from integrated health systems to pharmacy benefit management companies to health plans and managed care consulting. There are currently 23 professional sites in 15 states that offer Introductory Pharmacy Practice Experiences (IPPEs) or Advanced Practice Experiences (APPEs). AMCP has 84 student pharmacist chapters, providing opportunities for professional growth and promotion of managed care pharmacy within schools of pharmacy across the country. There are also 7 affiliate programs that are local, state, or regional organizations focusing on grassroots efforts in support of managed care pharmacy. They serve as a local educational resource for members, student pharmacists, and schools or colleges of pharmacy.

AMCP participates in a number of coalitions on behalf of managed care pharmacy. Coalitions allow AMCP's voice to be heard on a broader range of issues. In addition, by joining 